\title{
Development of the neonatal lamb and piglet
}

By D. B. Lindsay and V. H. Oddy, AFRC Institute of Animal Physiology, Babraham, Cambridge $C B 24 A T$

In some ways, the neonatal period may be regarded as an extension of the intrauterine period. As then, the young are nutritionally dependent on what the mother may provide in that growth rate may be still limited by maternal nutrition. It is true that there is an additional constraint, the capacity of the neonate to take what is offered. Nevertheless, growth may be very similar in late pregnancy and in the early post-natal period. This may be seen if we compare typical growth in the piglet and the lamb, from about $5^{\circ} \mathrm{d}$ of pregnancy over the next roo or so days (Fig. 1). The two rates are quite similar if we ignore the fact that term for the pig is about I $15 \mathrm{~d}$ and for the sheep $147 \mathrm{~d}$.

The comparison may be extended from the findings of Hodge (1974). He compared piglets and lambs given milk artificially, from 5-50 d after birth. The most striking difference was that the voluntary feed intake (per unit metabolic

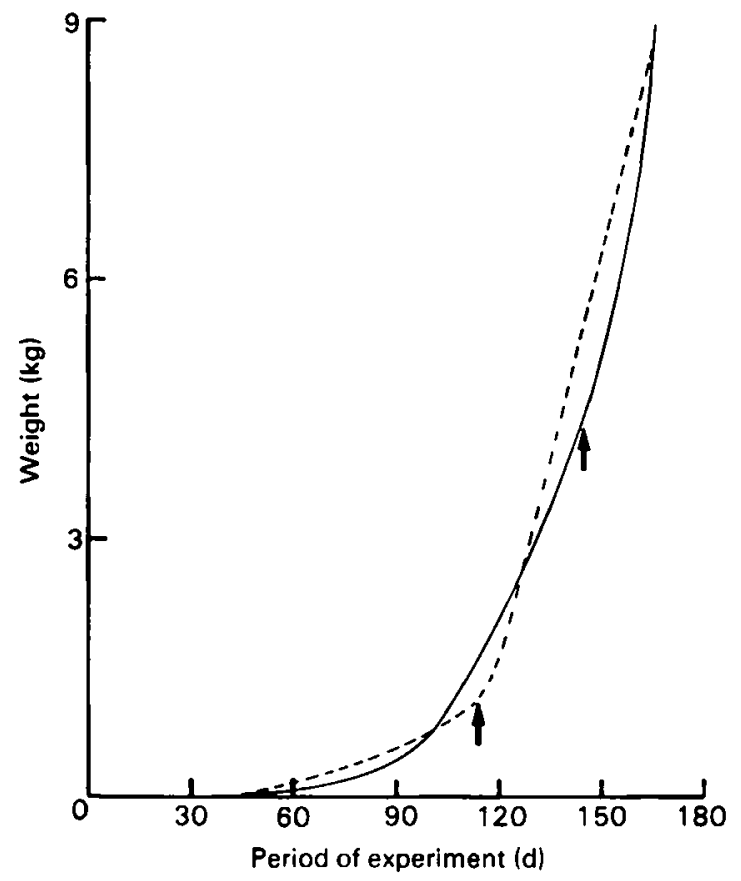

Fig. I. The rate of growth of lambs (-) and piglets (- - ) around term. Values for the piglet are taken from Cunha (1977) and Pond \& Houpt (1978). Those for the lamb from Metcalfe et al. (1962) and D. B. Lindsay and V. H. Oddy (unpublished results). $\uparrow$, Term.

- Present address: CSIRO Division of Tropical Animal Science, Tropical Cattle Research Centre, PO Box 5545, Rockhampton Mail Centre, Queensland 470 I, Australia. 
weight) was greater in piglets (initially by about $9 \%$ (not significant) but subsequently by $50-60 \%$ ) in part due to a decline in feed intake in the lambs. Food conversion efficiency at ad lib. intake was very similar, but was greater in the piglets if comparison was made at restricted feed intake. Protein and fat depositions were substantially greater in the piglets largely because of increased feed intake. The only other important difference was in the distribution of protein, for substantially more was found in the skin and wool of the lambs.

There is one further feature to consider: the lamb will eventually undergo additional growth of the gastrointestinal tract, specifically of the stomachs. We know that this does not occur to any extent until weaning, but it is important if one compares the growth of milk-fed and grass-fed (ruminating) lambs. Chambers \& Bickerstaffe (1982) and Chambers (1985) have made such a comparison, attempting to compare the two classes of lamb at similar digestible energy intakes. Total protein deposition was similar for equal empty-body-weight; however, the distribution was different, with nearly twice as much gastrointestinal protein in the grass-fed lambs and more carcass protein in the milk-fed lambs.

\section{Metabolic changes in the neonatal period}

Carbohydrate. In sheep, differences in carbohydrate metabolism between the sucking and weaned periods have long been recognized. In particular, the sucking lamb has a much higher blood glucose than the adult, and quite comparable to the pig. Moreover, there is a sharper fall in the post-absorptive state than is seen after weaning. There is no reason to doubt that this is a consequence of the direct absorption of dietary carbohydrate before weaning. The development of gluconeogenesis appears to vary between species. In the lamb it is now fairly certain that there can be development before birth. In the pig, studies by Pegorier et al. (1982) with hepatocytes suggest that while there is a low but significant rate of gluconeogenesis at birth, it is only $30-50 \%$ of that attained over the following $48 \mathrm{~h}$. This increase is only seen in piglets allowed to suck; there is very little increase in starved animals. This dependence on sucking, it is suggested, is apparently not due to defective development of gluconeogenic enzymes in non-sucking piglets (Mersmann, 1971; Robinson et al. 1981) but is partly due to a need for long-chain fatty acids (newborn pigs are very low in fat content), and partly to excessive glycolysis in the liver of fasted neonatal piglets. The practical consequence of this is a marked sensitivity of the neonatal piglet to adequate sucking for if this is inadequate a severe hypoglycaemia develops in the first $24 \mathrm{~h}$ after birth. From the observations of Hodgson \& Mellor ( 1985 ) it seems likely that there is substantial gluconeogenesis in the lamb in the first few hours after birth (a glucose production of $7.5 \mathrm{mg} / \mathrm{kg}$ per $\mathrm{min}$ in unsuckled lambs). Chambers (1985) found that the rate of glucose production in milk-fed lambs correlated with age, empty-body-weight and milk intake. Multiple regression analysis, however, showed only intake was significant. In this respect preruminating lambs behave much like ruminating animals where glucose production is known to be correlated with metabolizable energy intake (Horsfield et al. 1974). Mean glucose production 


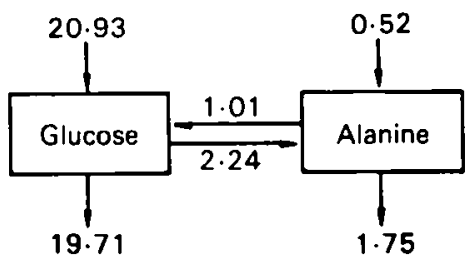

Neonate

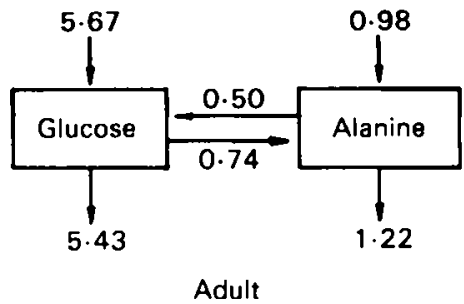

Fig. 2. Flux and interconversion of glucose and alanine (matoms carbon $/ \mathrm{h}$ per kg body-weight ${ }^{0.79}$ ) in 8-d-old lambs and mature sheep.

per unit metabolic weight, however, is much greater in preruminant lambs (e.g. Jarrett et al. 1964; White \& Leng, 1980).

There are also changes in the importance of glucose as an energy source. Chambers (I985) estimated 4I (SE 2.0) \% carbon dioxide was derived from glucose in milk-fed and 18.8 (SE $\mathrm{I} \cdot 0) \%$ in grass-fed lambs. We have made similar estimates which show the same pattern (2I (SE 3.6) for 8-d-old lambs, and 8 (SE $0.6)$ for mature ruminants). There may be technical reasons for the absolute differences. In lambs, complete oxidation of the glucose flux could only have accounted for $37 \%$ of the oxygen consumption. Actual recovery of ${ }^{14} \mathrm{C}$ in ${ }^{14} \mathrm{CO}_{2}$ was about $70 \%$, which is only slightly greater than that in ruminating sheep.

As well as oxidation, another important feature of glucose metabolism is its recycling through lactate and alanine. We have examined the extent of this in neonatal lambs, compared with mature and pregnant ewes, in experiments involving $\left[{ }^{14} \mathrm{C}\right]$ glucose and $\left[{ }^{14} \mathrm{C}\right]$ alanine. If one sets up a simple two-compartment system (Fig. 2) there is increased glucose-alanine exchange in the neonatal lamb. Rates of transfer are at least twofold greater than that in mature ruminants. This may be a consequence of the diminished availability of alanine derived from sources other than glucose in the neonate, with an increased irreversible loss. This is greater even when corrected for alanine oxidation, and is probably a reflection of an increased use for protein synthesis. We made no studies with $\left[{ }^{14} \mathrm{C}\right]$ lactate but since the proportion of lactate derived from glucose is slightly greater in neonates (about $70 \%$ compared with $50 \%$ in adults), lactate recycling is at least as significant as in older animals. This is supported by studies of glucose metabolism by the hind-limb muscle. In neonates glucose uptake is significantly greater, while lactate output, although variable, is at least as large as in adult animals. The large 
uptake of glucose is particularly interesting. Kempton et al. (1978) suggested there may be a specific need for glucose in growing (ruminating) lambs, on the basis of a relation between rate of glucose production and growth. This could merely have reflected the relations between growth and milk intake and glucose production and energy intake. We observed a similar (although weaker and non-significant) relation between glucose production and growth in 1-week-old lambs. We assumed the relation was probably artefactual, and tried to show this by relating glucose uptake by muscle to growth rate. Surprisingly, the relation was quite significant $(P<0.02)$; moreover a comparable study of 3 -hydroxybutyrate uptake (supplying about $20 \%$ of energy needs in neonatal lamb muscle) showed only a weak non-significant trend. We have to be cautious about this relation because blood flow was not measured. Moreover, the relation is not seen in milk-fed lambs 4-5 weeks old. Nevertheless, it seems possible that there is some relation between glucose uptake and muscle growth, at least in the early neonatal stage and this may only partly be due to the energy thereby made available. One possibility is that glucose- $\mathrm{C}$ is used for non-essential amino acid synthesis. It may be recalled that in our glucose-alanine studies most alanine-C was apparently derived from glucose.

One other feature of carbohydrate metabolism is the importance of insulin. As far as glucose is concerned, our current studies using the arterial-venous $(A-V)$ difference technique across muscle suggest that neonatal lamb muscle responds no better to insulin than does the adult muscle. Scharrer \& Huntemann (1977) showed that in isolated cricothyroid muscle of $\mathrm{I}$-week-old (but not older) lambs, insulin stimulated sugar (3-methyl glucose) transport more than in muscle of adult sheep. However, we have not made studies of the effect of insulin in 1-week-old lambs. In older milk-fed lambs, circulating insulin concentrations are substantially higher than in grass-fed sheep (Chambers \& Bickerstaffe, 1982). This may imply that milk-fed lambs have some features in common with obese humans, where elevated insulin concentrations are a sign of insulin resistance. Such resistance, as in humans, might be primarily in muscle, with adipose tissue unaffected.

Protein metabolism. Chambers (1985) observed there was no difference in tyrosine flux per unit metabolic weight in milk-fed compared with grass-fed lambs. In studies we have made with milk-fed lambs, using $\left[{ }^{14} \mathrm{C}\right]$ leucine, we have found a substantially greater flux than in adult sheep. Leucine oxidation, however, was not significantly different in milk-fed lambs and adults. We are currently using the neonatal lamb as a model for muscle growth, particularly in assessing the factors affecting protein synthesis and degradation. For analysing exchange in muscle, we used a simple compartmental model which assumes there is one leucine pool which receives leucine from blood and from proteolysis, and is used both to supply leucine for protein synthesis and to produce ketoleucine which is either released or oxidized. This model was applied to several lambs and has been used to test for possible interactions between muscle leucine and protein metabolism. It was particularly gratifying to find that there was no significant correlation between the rates of protein synthesis and degradation, so that these processes can be studied independently. Furthermore, the flux ratio, ketoleucine:leucine within muscle, and 
the proportion of leucine oxidized were both found to be significantly negatively related to the fractional rate of gain. Thus indices of degradation appear to be of particular importance in determining muscle growth.

What factors may determine the rate of muscle protein synthesis? One possibility is the arterial concentration of one or more amino acid. There was a very significant positive correlation between leucine arterial content and the $A-V$ difference across the muscle. A similar relation has also been seen between arterial tyrosine and its $\mathrm{A}-\mathrm{V}$ difference in growing lambs. These relations are consistent with the availability of amino acids being limited by their blood concentration. However, a close, that is, a local infusion of leucine into hind-limb muscle of fed lambs had no effect on leucine uptake. This suggests either that both uptake and concentration are controlled by independent means or that blood leucine (or tyrosine) concentration is determined by the extent to which the amino acid is taken up by peripheral tissues (of which muscle is an index).

Chambers (1985) has shown that in muscle, protein synthesis (as assessed by the incoporation of $\left[{ }^{14} \mathrm{C}\right]$ tyrosine) is slightly but significantly greater in milk-fed than in grass-fed lambs. One possible factor in determining this could be insulin, which we have seen is at higher concentrations in milk-fed lambs. Vincent (1985), working in our laboratory, has found that in growing (ruminating) lambs there is some correlation between plasma insulin and incorporation of tyrosine. She found that uptake of $\left[{ }^{14} \mathrm{C}\right]$ tyrosine (which we believe is closely related to the rate of protein synthesis) was also related to plasma insulin. To obtain a significant correlation, however, she needed to include results obtained with diabetic animals, and also those in which plasma insulin was unusually high. We believe that while there may be a permissive need for insulin, variation in normal plasma concentrations plays no part in determining the rate of protein synthesis. The possible effects at high insulin concentration may arise because insulin can weakly simulate the effects of somatomedin C (insulin-like growth factor I, IGF-I; Perdue, 1984) by binding with the latter's receptor, albeit with a much higher effective $\mathrm{K}_{\mathrm{m}}$. Testing this hypothesis, however, at the present price of IGF-r may be delayed until the advent of a nutritional fairy godmother!

\section{REFERENCES}

Chambers, J. A. ( ( $985_{5}$ ). Glucose, protein and energy metabolism in suckling and ruminating lambs. PhD Thesis, Lincoln College, University of Canterbury, New Zealand.

Chambers, J. A. \& Bickerstaffe, R. (1982). Proceedings of the Nutrition Society of Australia 7, 148. Cunha, T. J. (1977). Swine Feeding \& Nutrition, p. 256. New York and London: Academic Press. Hodge, R. W. (1974). British Fournal of Nutrition 32, $112-126$.

Hodgson, J. C. \& Mellor, D. J. (1985). Proceedings of the Nutrition Society 44, $90 A$.

Horsfield, J., Infield, J. M. \& Annison, E. F. (1974). Proceedings of the Nutrition Society 33, 9-1 5. Jarrett, I. G., Jones, J. F. \& Potter, B. J. (1964). Biochemical fournal 90, 189-194.

Kempton, T. G., Smith, G. H. \& Leng, R. A. (1978). Proceedings of the Australian Society of Animal Production 7, 354 .

Mersmann, H. J. (1971). American Fournal of Physiology 220, 1297-1 302. 
Metcalfe, J., Meschia, G., Hellegers, A., Prystowski, H., Huckabee, W. \& Barron, D. H. (rg62). Quarterly fournal of Experimental Physiology 47, 305-313.

Pegorier, J. P., Duee, P. H., Girard, J. \& Peret, J. (1982). Fournal of Nutrition $112,1038-1046$.

Perdue, J. F. (1984). Canadian Yournal of Biochemistry and Cell Biology 62, 1237-1245.

Pond, W. G. \& Houpt, K. A. (1978). The Biology of the Pig, p. 98. Ithaca, New york: Comstock Publishers.

Robinson, J. L., Duee, P. H., Schreiber, O., Bois-Joyeux, B., Chanez, M., Pegorier, J. P. \& Peret, J. (1981). Fournal of Development and Physiology 3, 191-201.

Scharrer, E. \& Huntemann, H. (1977). Pfïgers Archiv für die Gesamte Physiologie des Menschen und der Tiere $369,6 \mathrm{I}-64$.

Vincent, $\mathrm{R}$. (1985). Protein metabolism in sheep. $\mathrm{PhD}$ Thesis, University of Cambridge.

White, R. G. \& Leng, R. A. ( 1980 ). Comparative Biochemistry and Physiology 67, 223-229. 